\title{
ForGirls: impulsionando meninas para a área de exatas através da metodologia STEM
}

\author{
Ialy C. Sousa ${ }^{1}$, Lílian H. Teixeira ${ }^{1}$, Jerry A. Souza ${ }^{1}$, Moacy O. Silva ${ }^{1}$, Mary Karlla A. \\ Guimarães ${ }^{1}$, Iana Daya C. F. Passos ${ }^{1}$ \\ ${ }^{1}$ Instituto Federal da Paraíba - Campus Campina Grande (IFPB) \\ R. Tranquilino C. Lemos, 671 - Dinamérica - 58432-300 - Campina Grande - PB - Brasil \\ \{ialy.sousa, lilian.teixeira, jerry.souza\}@academico.ifpb.edu.br, \\ \{moacy.silva, mary.guimaraes, iana.passos\} @ifpb.edu.br
}

\begin{abstract}
The inducement for female participation in the STEM area has been expanding, but it is still unimposing. In this way, the objective of this project is to awaken vocational interest and promote the access of STEM female students to public schools to the STEM methodology. The method adopted involved a field study, where expository classes are given with the realization of experiments that stimulate learning and fixing the content, bringing a greater integration and development for the girls in their first school years.
\end{abstract}

Resumo. O incentivo à participação feminina na área da STEM vem crescendo, porém ainda é modesta. Desse modo, o objetivo desse artigo é apresentar o projeto que destinase à despertar o interesse vocacional e promover o acesso de estudantes do sexo feminino do ensino fundamental de escolas públicas à metodologia STEM. O método adotado envolveu um estudo de campo, onde são ministradas aulas expositivas com a realização de experimentos que estimulam o aprendizado e a fixação do conteúdo, trazendo uma integração e desenvolvimento maior para as meninas nos seus primeiros anos escolares.

\section{Introdução}

O acesso ao ensino superior vem aumentando cada vez mais ao longo do tempo tanto na modalidade presencial, quanto na modalidade a distância, e de acordo com o Censo da Educação Superior de 2017, pessoas do sexo feminino são a maioria dos ingressantes no ensino superior representando $55,2 \%$ do total. Porém, os cursos de graduação da área de ciências exatas, principalmente, na área de Engenharia Mecânica (89,7\%), Engenharia Civil $(69,5 \%)$ e Engenharia de Produção (65\%), possuem predominância masculina, dentre os 20 cursos mais numerosos de acordo com os dados do INEP (2019).

Estudos apontam que as mulheres pouco ocupam as áreas das ciências, tecnologia, engenharia e matemática, por razões sociais, culturais e estereótipos de diferenças de inaptidão, ausência ou desconhecimento de modelos e mentores, entre outros, embora suas realizações acadêmicas nos campos do STEM (Ciências, Tecnologia, Engenharia e Matemática, do inglês, Science, Technology, Engineering \& Mathematics) não mostram diferença significativa entre indivíduos do sexo masculino e feminino (ISAACSON et. al, 2019).

De posse desses dados, nossa problemática parte da possibilidade de incentivar meninas que queiram compreender o universo do STEM de forma simples, visando diminuir a distância 
entre essas crianças e os saberes referentes a essas áreas. Para tanto, buscamos proporcionar o contato direto dessas crianças com os conceitos de ciências, tecnologia, engenharia e matemática, através de um curso teórico-prático, possibilitando assim, a inclusão e o interesse delas.

Segundo Brito (2006), vivemos em um mundo que as tecnologias influenciam no nosso cotidiano, sendo imprescindível, assim, que a educação também inclua a democratização da aquisição do conhecimento, da produção e da interpretação das tecnologias.

\section{Revisão de literatura}

Ao longo da história da tecnologia, têm-se vários registros da importância da mulher no alcance de grandes feitos. A exemplo de Ada Lovelace, a matemática que criou o primeiro algoritmo a ser processado por uma máquina, sendo a primeira pessoa a programar ou Grace Hopper uma das criadoras do COBOL (Common Business Oriented Language), que juntamente com a sua equipe descobriram o famoso caso da mariposa dentro do MARK II, fato que resultou no surgimento do termo "bug". Não podemos deixar de citar também Katherine Johnson, que foi a única responsável pela precisão de navegação astronômica e várias outras mulheres do passado e atuais (ENGEL, 2013; LOPES, 2018; LUISA, 2018).

A participação de mulheres nas áreas de STEM existe, porém, ainda é menor que a presença masculina. Essa diferença é significativamente maior em campos tecnológicos como ciência da computação e engenharia do que em matemática e ciências (MASTER et. al, 2017). A representação das mulheres em STEM é uma questão complexa, existindo grandes variações entre os seus campos. Em 2012, as mulheres obtiveram 59\% de bacharelado em ciências biológicas, $43 \%$ em matemática e estatística e 41\% em física (National Science Foundation, 2015). Em contraste, a representação das mulheres foi muito menor em campos tecnológicos como ciência da computação (18\%) e engenharia (19\%).

Mas nem sempre foi assim, na década de 70 a presença feminina era maior que a masculina, por exemplo, no curso de ciências da computação do Instituto de Matemática e Estatística (IME) em São Paulo, na primeira turma que contava com 20 alunos, 14 eram mulheres, ou seja $70 \%$ da turma. Porém, entre as décadas de 70 e 80 houve essa inversão de gêneros na área da tecnologia que vemos até hoje, com o surgimento do computador pessoal, como ilustra a figura 1 (SANTOS, 2018).

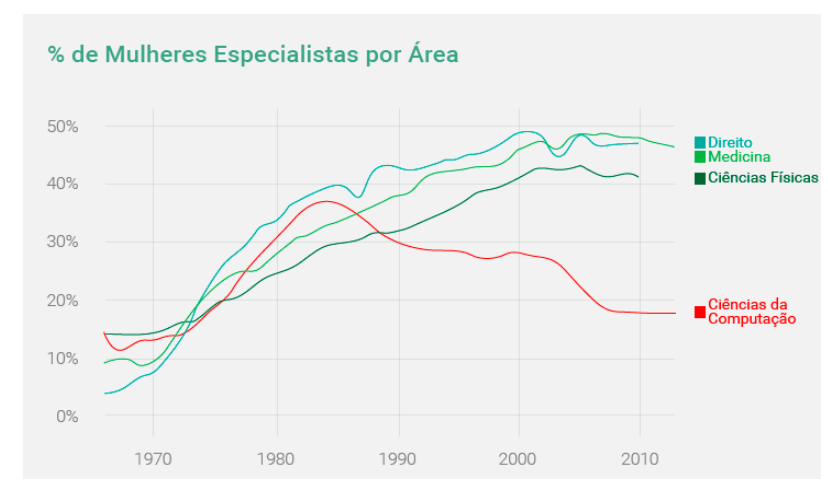

Figura 1. Porcentagem de mulheres especialistas por área

O estímulo às meninas desde seus primeiros anos escolares é fundamental para que elas se interessem e sigam uma carreira na área de exatas. Uma das formas é através de aulas práticas com o uso de experimentos. Segundo Seré et. al (2003), a inclusão de atividades 
experimentais incita o aluno a não permanecer apenas no mundo dos conceitos e da linguagem, mas sim, poder relacionar esses dois mundos com o mundo empírico.

\section{Metodologia do projeto}

O processo metodológico utilizado nesse projeto se baseia principalmente em estudo de campo, onde são ministradas aulas expositivas com a realização de experimentos que estimulem o aprendizado e a fixação do conteúdo.

Esse projeto visa cumprir as atividades de iniciativa social que estão na base das atividades e pesquisas das instituições públicas brasileiras, que tem como tríplice o ensino, a pesquisa e a extensão, enquadrando-se nesse último, que visam a democratização do conhecimento, atingindo a população em geral. Para a realização desse projeto, os autores seguiram uma série de atividades, que estão listadas no quadro a seguir.

Quadro 1. Atividades desenvolvidas no projeto

\begin{tabular}{|c|c|}
\hline Atividade & Descrição \\
\hline 1 & $\begin{array}{l}\text { Inicialmente foi realizada a atualização bibliográfica acerca da área de STEM, as } \\
\text { técnicas e mecanismos mais usados nos trabalhos e pesquisas relacionadas a este } \\
\text { campo de saber. }\end{array}$ \\
\hline 2 & $\begin{array}{l}\text { Realização de estudos e discussões sobre a fundamentação teórica utilizadas em } \\
\text { implementações propostas na literatura que abordem temas relacionados à área do } \\
\text { STEM e as mulheres. }\end{array}$ \\
\hline 3 & $\begin{array}{l}\text { Realização de testes e simulações das atividades desenvolvidas ao longo do projeto, } \\
\text { com o intuito de validar os experimentos desenvolvidos no projeto. }\end{array}$ \\
\hline 4 & Aplicação do projeto através de aulas teórico-práticas nas escolas públicas. \\
\hline 5 & $\begin{array}{l}\text { Elaboração de relatórios, com o objetivo de descrever o andamento das atividades } \\
\text { relacionados ao desenvolvimento deste projeto. }\end{array}$ \\
\hline 6 & $\begin{array}{l}\text { Publicação dos resultados obtidos sob a forma de artigos em periódicos, revistas ou } \\
\text { congressos nacionais e /ou internacionais. }\end{array}$ \\
\hline
\end{tabular}

O curso teórico-prático é realizado através da formação de 2 (duas) turmas por ano contendo vinte alunas, cada uma com duração de 4 (quatro) meses. Os encontros são semanais no turno oposto ao das aulas das alunas e terão duração média de 2 a 3 horas. Esse curso será aplicado em escolas públicas que se encontram em um bairro periférico, onde há escassez de oportunidade para a população, nas séries do Fundamental II e Ensino Médio. A escolha dessas séries ocorreu baseado tanto no fato de que é a partir do $9^{\circ}$ ano (fundamental II), que as disciplinas de física e química são abordadas no currículo escolar quanto pelo fato de que é normalmente nessa faixa etária que começa-se a pensar no quesito carreira.

Os assuntos normalmente abordados nessas aulas são: Fundamentos da eletricidade; Uso de equipamentos e componentes (multímetro, osciloscópio, fonte, resistores, capacitores, transistores, baterias, LEDs etc.); Grandezas e medidas; Reações químicas; Grandezas físicas; Arduino (microcontrolador); Lógica de programação.

E, para conclusão do curso é realizado um projeto final, com o intuito de aplicar os conhecimentos adquiridos ao longo das aulas. Esse projeto final consistirá na fabricação de um robô ambulante feito de papelão ou um cubo de LEDs. 
Inicialmente, é realizado um questionário com perguntas de múltipla escolha sobre os temas que serão abordados durante o curso e, ao final do curso esse mesmo questionário é reaplicado para mensurar o nível de absorção do conteúdo. Essa análise é feita através do método da Teoria de Resposta ao Item (TRI), que tem como princípio básico que a probabilidade de acerto de uma questão está totalmente ligado ao nível de domínio que o indivíduo tem sobre um determinado assunto.

\section{Resultados esperados e conclusão}

Tendo em vista a relevância da inclusão de meninas na área das exatas, espera-se que ao final do curso elas possam demonstrar interesse de seguir os estudos nesta área, tornando-se assim, possíveis engenheiras, cientistas ou pesquisadoras.

Alguns experimentos foram executados com o intuito de aplicar os conceitos de matemática, física, química, elétrica e programação apresentados. Como por exemplo, o experimento da vela (figura 2), o experimento da lâmpada de larva (figura 3) e o experimento do cubo de LEDs (figura 4).

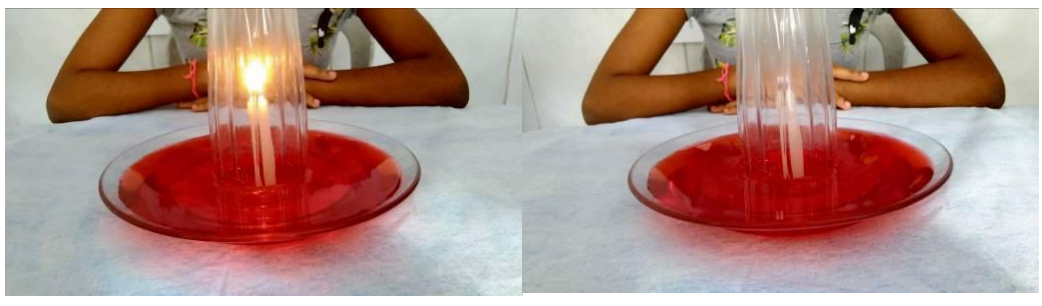

Figura 2. Aluna realizando experimento da vela

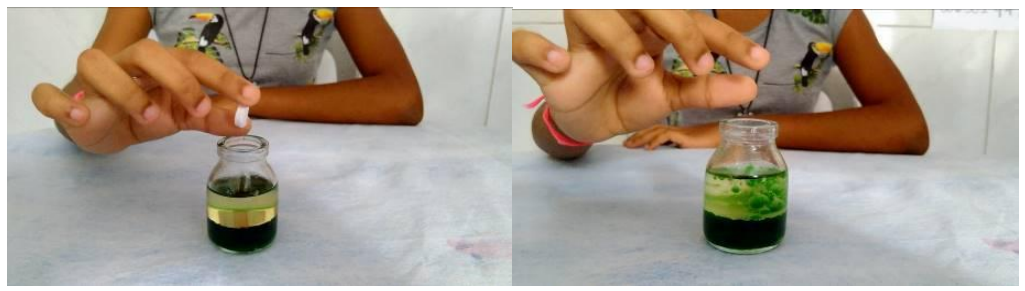

Figura 3. Aluna realizando experimento da lâmpada de larva

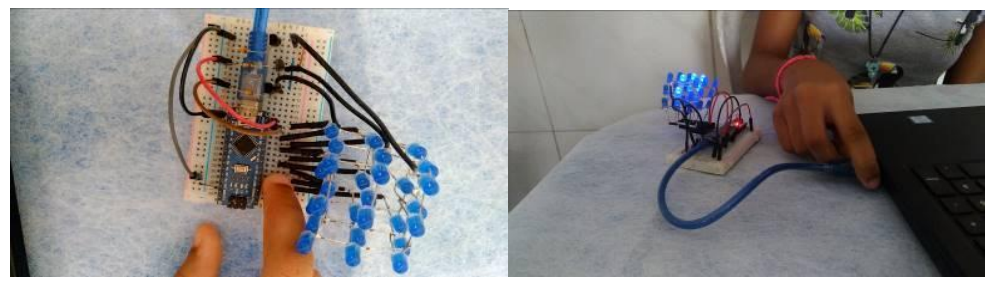

Figura 4. Aluna realizando experimento do cubo de $L E D s$

Para além dos conhecimentos adquiridos no decorrer do projeto, a inclusão de meninas na área das exatas, através da metodologia de ensino STEM, contribui para o aumento da diversidade de indivíduos atuando com as novas tecnologias.

O projeto proposto, trará uma integração e desenvolvimento maior para as meninas nos seus primeiros anos escolares, principalmente para as de escolas públicas onde o acesso a esse tema é mais limitado e muitas vezes escasso. 
O projeto também tem uma importância social porque visa diminuir a distância entre essas estudantes e o ensino superior, através da apresentação de uma opção de área do conhecimento que não está presente no cotidiano escolar, proporcionando uma aprendizagem diferenciada.

\section{Referências bibliográficas}

BRITO, G. S; Purificação, I. Educação e Novas Tecnologias: um repensar. Curitiba: IBPEX, 2006.

INEP. Ministério da educação. Censo da educação superior: resumo técnico. Brasília DF, 2019.

ISAACSON, S. FRIEDLANDER, L. MEGED, C. HAVIVI, S. ZADA, A. L. C. RONAY, I. MAMAN, S. BLUMBERG, D. G. She space: A multi-disciplinary, project based learning program for high school girls. Acta Astronautica, 2019.

LUISA, I. Katherine Johnson fez muito mais que ajudar o homem a chegar à lua. 2018. Disponível em: <https://super.abril.com.br/historia/katherine-johnson-fez-muito-mais que-ajudar-o-homem-a-chegar-a-lua/> - acesso em 24 out. 2019.

PROGRAMARIA. O que tirou as mulheres da tecnologia? Comunidade Programaria. 2015. Disponível em: < https://www.programaria.org/o-que-tirou-as-mulheres-da tecnologia/> - acesso em 18 fev. 2020.

SANTOS, C. M. Por que as mulheres “desapareceram” dos cursos de computação? Jornal da USP. São Paulo- SP, 2018. Disponível em: $<$ https://jornal.usp.br/universidade/por-que-as-mulheres-desapareceram-dos-cursos-de computacao/> - acesso em 18 fev. 2020.

SERÉ, M. G. COELHO, S. M. NUNERS, A. D. O papel da experimentação no Ensino de física. Caderno Brasileiro de Ensino de Física. Florianópolis - SC. v. 20, n.1, p.31 42, 2003.

TAKE. A volta das mulheres na computação. Take blog. 2019. Disponível em: <https://take.net/blog/4devs/a-volta-das-mulheres-na-computacao/> - acesso em 18 fev. 2020. 